\title{
DITADURA E REIVINDICAÇÕES POR DEMOCRACIA: MEMÓRIAS FEMINISTAS E A QUESTÃO DO TRABALHO DOMÉSTICO (1964-1990)
}

\author{
Soraia Carolina de Mello
}

Pensar e discutir o trabalho doméstico das mulheres como uma reivindicação democrática, a partir da história dos feminismos que se organizam no Brasil durante o período da ditadura civil-militar, é um recorte não tradicional para se pensar a memória sobre a ditadura brasileira. Sob essa perspectiva, são objeto da análise aqui apresentada memórias de feministas que viveram esse período e estiveram ligadas, de maneiras muito distintas, à luta contra a ditadura e à construção da abertura política, assim como as interlocuções entre as problematizações feministas acerca do trabalho doméstico e a perspectiva de sociedade democrática que se abre no período. Sob o slogan "feminismo no país e em casa", os debates feministas articularam público e privado ao denunciar a carga de trabalho doméstico que era executada quase que exclusivamente pelas mulheres e suas consequências para o pleno acesso dessas à cidadania.

A proposta se apresenta sob a perspectiva da história das mulheres e das relações de gênero, assim como dos debates historiográficos sobre memória e história oral, cruzando bibliografia de referência sobre os feminismos do período, a ditadura e a abertura democrática. Desse modo, se pretende pensar a história do debate acerca do trabalho doméstico encabeçado por feministas dessa geração como um ponto fulcral para as mulheres nas novas perspectivas democráticas que se construíram no âmbito político brasileiro na segunda metade dos anos $1980 .^{2}$

\section{Organizações feministas e de mulheres desde os anos 1960 no Brasil}

Diante da efervescência política brasileira, repleta de novas ideias progressistas e acompanhada pela modernização e industrialização crescente desde a década de $1950^{3}$, foi deflagrado, em $1^{\circ}$ de abril de 1964, o golpe civil-militar no país, que pôs fim ao governo democrático do então presidente João Goulart. Depois do golpe de 1964, o Brasil só voltou a ter um presidente civil, eleito indiretamente, em 1985. Apesar das especificidades da ditadura brasileira, as motivações do ataque militar ao governo democrático foram muito semelhantes àquelas ocorridas em outros países do Cone Sul neste período ${ }^{4}$, marcadas pelas disputas do mundo bipolarizado, a intervenção estadunidense na América Latina e o crescimento ou fortalecimento do conservadorismo em setores da população civil.

Foi nesse cenário de ataque às liberdades democráticas e de terrorismo de Estado, todavia, que se organizaram e se estabeleceram no Brasil mobilizações feministas que são, grosso modo, classificadas por teóricas e historiadoras de Segunda Onda. ${ }^{5}$ Essa emergência dos feminismos nesse contexto de

\footnotetext{
${ }^{1}$ Doutora em História Cultural pela Universidade Federal de Santa Catarina (UFSC). Pós-doutoranda do Programa de Pósgraduação Interdisciplinar em Ciências Humanas (PPGICH) da Universidade Federal de Santa Catarina (UFSC). E-mail: <soraiaa.mello@gmail.com>.

${ }^{2}$ Uma primeira e resumida versão desse artigo foi apresentada nas Vo Jornadas CINIG de Estudios de Género y Feminismos y III $^{\circ}$ Congreso Internacional de Identidades na Facultad de Humanidades e Ciencias de la Educación (FaHCE) da Universidad Nacional de La Plata (UNLP), na Argentina. Outra versão desse debate foi apresentada em espanhol para a revista Descentrada, Revista Interdisciplinaria de Feminismos y Género da FaHCE.

${ }^{3}$ MELLO; João Manuel Cardoso de; NOVAIS, Fernando A. Capitalismo tardio e sociabilidade moderna. In: SCHWARCZ, Lilia Moritz (org.). História da vida privada no Brasil: contrastes da intimidade contemporânea. V. 4. São Paulo: Companhia das Letras, 1998, p. 559-658.

${ }^{4}$ COGGIOLA, Osvaldo Luis Angel. Governos Militares na América Latina. São Paulo: Contexto, 2001.

${ }^{5}$ Para críticas ao uso da classificação dos feminismos em Ondas na América Latina ver PEDRO, Joana Maria. Narrativas fundadoras do feminismo: poderes e conflitos (1970-1978). Revista Brasileira de História. São Paulo: ANPUH, v.26, n.52, jul/dez 2006. Essa mesma autora, em PEDRO, Joana Maria. Relações de gênero como categoria transversal na historiografia contemporânea. Topoi, v. 12, n. 22, jan.-jun. 2011, p. 10, traz debates de feministas não brancas sobre a noção de ondas, as quais partiriam de um centro irradiador. Nesse sentido, ironicamente pergunta-se se as feministas brancas do "Norte" se consideravam as "inventoras" do questionamento à opressão sexista, criadoras das "ondas irradiadoras" de feminismo. Mais críticas sobre as narrativas fundantes da historiografia feminista, em uma perspectiva ocidentalizada, podem ser encontradas SÆCUlUM - Revista DE HistóRIa [39]; João Pessoa, jul./dez. 2018. 
repressão política pode parecer paradoxal, mas o paradoxo seria característica fundamental dos feminismos, já indicada em outros sentidos por Joan W. Scott. ${ }^{6}$ Também é característica da "modernização conservadora"7, com novas práticas, mas evitando transformações profundas, que se pôde observar concernente aos costumes e, em especial, às mulheres, neste período no Brasil.

Temos, sobre essa questão, bibliografia que busca explicar como foi justamente nesse cenário de perseguição às esquerdas que as mobilizações de mulheres, não entendidas como tão políticas ou tão perigosas quanto aquelas associadas ao comunismo ou ao socialismo, puderam existir, apesar do Estado de exceção e do terrorismo de Estado. O Ano Internacional da Mulher, estabelecido pela Organização das Nações Unidas (ONU) em 1975, impulsionou, segundo Cynthia Andersen Sarti ${ }^{8}$, a ocupação do espaço público e a publicização de movimentos ou engajamentos políticos feministas que trabalhavam ainda nos bastidores da clandestinidade. Desse modo, se havia antes de 1975 grupos de reflexão de mulheres ou feministas, assim como publicações e traduções de determinadas obras e o pioneirismo de algumas mulheres debatendo a "condição feminina", os agrupamentos de mulheres nomeadamente feministas aproveitaram o aval da ONU como oportunidade para levar esses debates a público. ${ }^{9}$

Essa relação com a ONU (ou uso da ONU) integra um discurso fundador dos feminismos dessa geração no Brasil, que está conectado com a história dos centros urbanos e intelectuais do país, nomeadamente o eixo Rio-São Paulo. Apesar de outras histórias mais periféricas, plurais e diversas dos feminismos e principalmente dos movimentos de mulheres também serem contadas, essa história mais hegemônica não deixa de ter acontecido, nem de ser repetida por muitas mulheres que participaram dela $e$ hoje a memoram e a escrevem a partir de suas posições de importância nas principais universidades do país. Marcamos essa caractrística para lembrar que essa narrativa não é a única na história dos feminismos desse período. É um "mito fundador" que nos interessa nesta comunicação, porque as três personagens cujas memórias serão observadas, aqui, fazem de alguma forma parte dessa história mais hegemônica dos femininos brasileiros, ainda que partindo de perspectivas muito distintas entre si. As três entrevistas foram realizadas em 2017, e apresentamos brevemente as entrevistadas, a seguir.

\section{As entrevistadas, procedimentos metodológicos e o recorte temático}

Fani Miranda Tabak ${ }^{10}$ nascida em 1972, é professora de literatura da Universidade Federal do Triângulo Mineiro (UFTM), com ênfase de pesquisa nos estudos de narrativa poética e historiografia, modernidade e estudos de gênero. Membro do Grupo de Trabalho "A Mulher na Literatura" da Associação Nacional de Pós-Graduação e Pesquisa em Letras e Lingüística (ANPOLL), que existe desde 1984. Possui interesse pela área de historiografia, participação e autoria de mulheres $e$ Independência na America Latina, sobretudo em um corpus não canônico. Ela é neta de Fanny Tabak, socióloga carioca apontada como fundadora do primeiro Núcleo de Estudos sobre a Mulher em uma universidade brasileira (PUC-Rio) no final da década de 1980; foi filiada ao PCB (Partido Comunista Brasileiro) e teve destacada atuação no movimento de mulheres na década de 1940, participando da fundação da Federação de Mulheres do Brasil; foi também uma das militantes apontadas como pioneiras dos feminismos brasileiros das décadas de 1970 e 1980, dedicando-se por muitos anos a estudar e militar nas questões referentes à participação das mulheres na ciência e na política. ${ }^{11}$

em HEMMINGS, Clare. Contando estórias feministas. Estudos Feministas, Florianópolis, v. 17, n. 1, p. 215, jan. 2009.

${ }^{6}$ SCOTT, Joan W.. O enigma da igualdade. Estudos Feministas, Florianópolis, v.13, n.1, p. 11, jan. 2005 e SCOTT, Joan W.. A cidadã paradoxal: as feministas francesas e os direitos do homem. Florianópolis, Ed. Mulheres, 2002.

${ }^{7}$ GOLDBERG, Anette. Feminismo e autoritarismo: a metamorfose de uma utopia de liberação em ideologia liberalizante. Rio de Janeiro. Dissertação (Mestrado em Ciências Sociais), UFRJ, 1987, p. 25 e DUARTE, Ana Rita Fonteles. Carmen da Silva: o feminismo na imprensa brasileira. Fortaleza: Expressão Gráfica e Editora, 2005, p. 109.

${ }^{8}$ SARTI, Cynthia Andersen. O feminismo brasileiro desde os anos 1970: revisitando uma trajetória. Estudos Feministas, Florianópolis, v.12, n.2, p. 35, jan. 2004.

${ }^{9}$ WOLFF, Cristina Scheibe; CRESCÊNCIO, Cintia Lima; PEDRO, Joana Maria. Ondas, mitos e contradições: feminismos em tempos de ditaduras no Cone Sul. In: ROCHA, Marcos Antonio Monte. (org.). Feminismos plurais. Fortaleza: Expressão Gráfia e Editora, 2016, p. 53-70.

${ }^{10}$ Entrevista com Fani Miranda Tabak, em Florianópolis, no dia 01/08/2017, realizada por Soraia Carolina de Mello, filmada por Elaine Schmitt e transcrita por Luana Balieiro Cosme.

${ }^{11}$ VASCONCELLOS, Bruna Mendes de; LIMA, Márcia Maria Tait. Fanny Tabak e os primeiros passos dos estudos sobre 312 SÆCUlUM - REVISTA DE HistóRIa [39]; João Pessoa, jul./dez. 2018. 
Nesse sentido, a entrevista discutiu feminismo inter-geracional e as percepções da entrevistada, como feminista, desses debates no tempo, na sua vida e também na de sua avó. As abordagens sobre a temática do trabalho doméstico são bastante pontuais, mas enriquecem nossos argumentos, como poderá ser observado adiante.

Hildete Pereira de Melo ${ }^{12}$, nascida em 1943, é economista e, desde 1972, professora da Universidade Federal Fluminense (UFF). Esteve envolvida com grupos de resistência à ditadura. Foi diretora financeira do Centro Internacional Celso Furtado de Políticas para o Desenvolvimento, entre 2004 e 2007; atuou na Secretaria de Políticas para as Mulheres (SPM) da Presidência da República entre 2009 e 2010 e depois entre 2012 e 2014. Possui atuação feminista destacada na academia e na política institucional, e esteve engajada em muitos grupos e diferentes frentes de militância das mulheres, incluindo os debates da Assembleia Nacional Constituinte de 1987. Atualmente é um dos principais nomes do Brasil na produção científica sobre trabalho das mulheres, com ênfase nas temáticas do trabalho doméstico, não remunerado e de cuidado. Sua entrevista é uma das mais extensas que realizamos para o projeto mas, como as demais, não foca especificamente na questão do trabalho doméstico.

Luci Teresinha Choinacki ${ }^{13}$, nascida em 1954, é agricultora, militante em prol da agricultura orgânica e familiar. Filha de agricultores, começou a atuar nas Comunidades Eclesiais de Base (CEB) e em movimentos sociais. Ingressou no Partido dos Trabalhadores (PT) em 1982 e participou da formação da Central Única dos Trabalhadores (CUT), da construção do Movimento de Mulheres Camponesas (MMC) e Movimento dos Trabalhadores Rurais Sem Terra (MST) de Santa Catarina. Foi a única mulher eleita em 1986 para a Assembleia Legislativa do Estado de Santa Catarina e deputada estadual constituinte em 1987. Em 1990 foi eleita para a Câmara dos Deputados, sendo reeleita para os mandatos de 1999, 2003 e 2011. Teve atuação central na construção da possibilidade de aposentadoria para trabalhadores rurais, em especial as mulheres, na Constituição de $1988^{14}$, e é autora do Projeto de Lei, de $2005^{15}$, que permitiu aposentadoria a donas de casa de baixa renda: o sistema especial de inclusão previdenciária de trabalhadores e trabalhadoras sem renda própria que se dediquem exclusivamente ao trabalho doméstico de sua residência.

Diferente das entrevistadas anteriormente citadas, cujas entrevistas foram realizadas em uma sala na Universidade $^{16}$, Luci Choinacki foi entrevistada, a seu pedido, em sua horta orgânica no bairro do Rio Vermelho, em Florianópolis, onde trabalha, atualmente, todos os dias da semana. Essa característica, assim como sua própria história de vida, que é muito diferente do perfil acadêmico/institucional de Fani Tabak e Hildete Pereira de Melo, pode ser observada em sua entrevista, que traz pontos de articulação importantes entre a militância política de base e a academia, como veremos adiante.

Este artigo é resultado do meu engajamento no projeto de pesquisa "Mulheres de luta: feminismo e esquerdas no Brasil (1964-1985)"17, que tem como objetivo analisar o feminismo percebendo a especificidade da sua constituição enquanto movimento social e conjunto de ideias no Brasil no período da ditadura militar $^{18}$, e suas interfaces com as organizações e movimentos de enfrentamento

Ciência, Tecnologia e Gênero no Brasil. Redes, Bernal, v. 22, n. 43, p. 13-32, dez. 2016.

${ }^{12}$ Entrevista com Hildete Pereira de Melo Hermes de Araújo, em Florianópolis, no dia 04/08/2017, realizada por Soraia Carolina de Mello, filmada por Elaine Schmitt e transcrita por Alina Nunes e Valéria Machado.

${ }^{13}$ Entrevista com Luci Teresinha Choinacki, em Florianópolis, no dia 25/09/2017, realizada por Soraia Carolina de Mello, filmada por Elaine Schmitt e transcrita por Jeferson Ramos.

${ }^{14} \mathrm{Um}$ pouco sobre essa questão pode ser lido em MEDEIROS, Silvia. Aposentadoria leva autonomia e independência às mulheres do campo. Catarinas, Florianópolis, 01/05/2017. Disponível em:

http://catarinas.info/aposentadoria-leva-autonomia-e-independencia-mulheres-campo/ Acessado em 08/04/2018.

${ }^{15} \mathrm{Em}$ 2006, a professora Hildete Pereira de Melo organizou um dossiê na revista Gênero da UFF focado na temática gênero e trabalho, no qual foi publicado na íntegra o Projeto de Lei que visava a possibilidade da aposentadoria das donas de casa de baixa renda, além de nota técnica sobre a questão. Gênero. Niterói, v.6, n.2 - v.7, n.1, p. 241-252, 2006. Disponível em http://www.revistagenero.uff.br/index.php/revistagenero/issue/view/27/showToc. Acessado em 08/04/2018.

${ }^{16}$ As entrevistas citadas foram realizadas durante o $13^{\circ}$ Congresso Mundos de Mulheres (MM) e Seminário Internacional Fazendo Gênero 11 (FG), em agosto de 2017, na Universidade Federal de Santa Catarina.

${ }^{17}$ Este projeto é coordenado pela professora Cristina Scheibe Wolff no Departamento de História da Universidade Federal de Santa Catarina (UFSC), com vigência entre 2017 e 2019, e foi contemplado pelo Edital 12/2015 CAPES (Coordenação de Aperfeiçoamento de Pessoal do Nível Superior), do Programa "Memórias Brasileiras - Conflitos Sociais", Processo 88887.130836/2016-00.

${ }^{18}$ Parte-se da perspectiva, aqui, de que o golpe de 1964 foi civil-militar porque, nas palavras de Carlos Fico (p. 469), "os civis deram o golpe também", contudo, "o regime que se seguiu foi eminentemente militar", no sentido de que os próprios civis SÆCUluM - Revista DE HistóRIa [39]; João Pessoa, jul./dez. 2018. 
da ditadura: partidos, organizações armadas, movimentos de familiares de presos e desaparecidos, grupos de exiladas/os, entre outros movimentos.

A principal problemática do projeto é a de que o feminismo tem sido um conflito social importante na sociedade brasileira, que se consolidou especialmente na sua interação com grupos de esquerda durante o período da ditadura (1964-1985) e que, neste período, trouxe significativas mudanças sociais. Dentre as temáticas estudadas está a questão do trabalho doméstico, que foi muito abordada pelos feminismos de matriz materialista, que se fortaleceram no Brasil no período em diálogo com as esquerdas, e interpretaram a dupla ou tripla jornada de trabalho através de cálculos do montante de trabalho não pago que as mulheres prestavam à socidade. Além do viés materialista, o trabalho doméstico foi também abordado dentro da percepção de sororidade, irmandade, da opressão específica às mulheres. Ou seja, das questões que eram entendidas como comuns a todas as mulheres, que marcaram com muita força as primeiras gerações dos feminismos de Segunda Onda nos países do Norte Global ${ }^{19}$ e também em alguns países latinoamericanos industrializados, como o caso do Brasil.

Desse modo, o trabalho doméstico recebe destaque nos discursos feministas da década de 1970 no Brasil e persiste, apesar dos avanços, como um problema não resolvido pelas mobilizações feministas: calculamos hoje, através da Pesquisa Nacional por Amostra de Domicílios (PNAD), do Instituto Brasileiro de Geografia e Estatística (IBGE), que as mulheres ainda gastam o dobro de horas semanais que os homens em tarefas domésticas, apesar da ampla inserção delas no mercado de trabalho (quase $83 \%$ do total de mulheres). ${ }^{20}$ Entendemos, portanto, a importância desse debate também para o presente.

Vale destacar, contudo, que as entrevistas aqui utilizadas não possuem, em seu roteiro geral - que foi elaborado para a pesquisa mais ampla -, questões específicas sobre trabalho doméstico, como pode ser observado no roteiro disponível ao final do artigo. Aconteceu, especialmente nos casos de Hildete Pereira de Melo e de Luci Teresinha Choinacki que eu, realizando as entrevistas, já conhecia a história de atuação das entrevistadas e sua sensibilidade à questão e, devido a meus interesses de pesquisa, busquei perguntar mais sobre trabalho doméstico. Essas informações são importantes porque, apesar das outras entrevistadas - realizamos até então dezessete entrevistas para o projeto - provavelmente terem posicionamentos e questões a colocar sobre o trabalho doméstico e os feminismos, elas não foram instigadas diretamente a falar sobre essa questão nas entrevistas, e então outras temáticas surgiram.

Por exemplo, a questão número 8 do roteiro de entrevista pergunta quais temas eram discutidos, $e$ então as próprias entrevistadas levantavam as temáticas que explorávamos. Partindo do entendimento de que recordamos e escrevemos história a partir de questões do presente, ${ }^{21}$ pudemos perceber também que muitas das temáticas apontadas foram aquelas com as quais as entrevistadas se ocuparam depois por muitos anos, ou então que interpretavam como marcantes para a história daquele período a partir do olhar do presente, ou mais próximo do presente, já que as entrevistas são de 2017.

que participaram do golpe foram afastados e os militares controlaram cada vez mais o poder, sem possibilidade de negociação. FICO, Carlos. Ditadura Militar: mais do que algozes e vítimas. A perspectiva de Carlos Fico. [Entrevista realizada em 24 de julho, 2013]. Revista Tempo e Argumento, Florianópolis, v.5, n.10, jul./dez. 2013. p. 464-483. Entrevistadores: Silvia Maria Fávero Arend, Rafael Rosa Hagemeyer e Reinaldo Lindolfo Lohn.

${ }^{19}$ Com Norte Global queremos designar, aqui, os países colonialistas, as metrópoles. Seriam aqueles lugares que ditaram as normas do colonialismo e se beneficiaram dele, em acepção muito mais histórico-política do que estritamente geográfica, em sentido semelhante ao utilizado por SANTOS, Boaventura de Sousa. Para além do pensamento abissal: das linhas globais a uma ecologia de saberes. Novos Estudos - CEBRAP, São Paulo, n. 79, p. 71-94, nov. 2007.

${ }^{20}$ Notícia do final do ano passado com um bom resumo desses dados, apesar de ser dos setores mais conservadores $e$ promotores do Golpe da imprensa brasileira, pode ser encontrada em: SILVEIRA, Daniel. Mulheres passam o dobro do tempo dos homens com tarefas domésticas, aponta IBGE. O Globo online, 07/12/2017. Disponível em: https://g1.globo.com/economia/noticia/mulheres-passam-o-dobro-do-tempo-dos-homens-com-tarefas-domesticas-apontaibge.ghtml Acessado em 08/04/2018.

${ }^{21}$ Questões já abordadas em BLOCH, Marc. Apologia da História, ou, O ofício de historiador. Rio de Janeiro: Zahar, 2001 e POLLAK, Michael. Memória, esquecimento, silêncio. Estudos Históricos, Rio de Janeiro, v.2, n.3, p. 3-15, jun. 1989; também tratada em obras mais recentes sobre história oral, memória e história do tempo presente no Brasil, como DELGADO, Lucília de Almeida Neves; FERREIRA, Marieta de Moraes (org.). História do tempo presente. Rio de Janeiro: Ed. FGV, 2014, ou na entrevista do ano passado FREITAS, Jeferson L. de; ARAÚJO, Cosma S. de; SALES, Telma B. "O que essa entrevista está documentando?": entrevista com a professora Verena Alberti. História Oral, v.20, n.2, p. 237-251, jul./dez. 2017. 


\section{Um problema para os feminismos: o trabalho doméstico}

Faz-se crucial para a justificativa desta análise, além de pensar a história dos feminismos desde os anos 1960 e principalmente 1970, e o contexto no qual as entrevistas aqui utilizadas foram produzidas, considerarmos também a importância dos debates acerca do trabalho doméstico para aquela geração $e$ ainda para a nossa. Em pesquisas anteriores, abordei as discussões feministas de Segunda Onda no Brasil e no Cone Sul sobre o trabalho doméstico ${ }^{22}$, através da produção impressa dos feminismos: periódicos, panfletos, dissertações, teses, artigos e livros. Posteriormente, trabalhei com o debate feminista sobre o trabalho doméstico na grande imprensa comercial brasileira ${ }^{23}$, focando no mesmo recorte temporal que as pesquisas anteriores, entre as décadas de 1970 e 1980. Essas pesquisas me possibilitaram mergulhar nas discussões acerca do trabalho doméstico, principalmente o não remunerado, e articular sua centralidade nas reivindicações feministas com as características dos próprios movimentos naqueles anos, em especial a busca por questões gerais, que afetassem todas as mulheres.

Um ponto que me pareceu marcante, principalmente nos anos 1970, foi a percepção das mulheres que se identificavam publicamente como feministas de que o problema do trabalho doméstico era um problema das mulheres como categoria, um problema coletivo, mas não delas mesmas individualmente. Falo principalmente dos anos 1970 porque pude observar, nas produções escritas dos feminismos, que na década de 1980 a temática do trabalho doméstico não pago das mulheres perde espaço para outros debates, como violência, sexualidade, saúde e direitos reprodutivos. Tal percepção é corroborada - e aqui estou fazendo uso da memória da entrevistada para, de fato, enfatizar o que percebi em pesquisa de arquivo - pelo depoimento de Hildete Pereira de Melo, quando ela comenta:

O pessoal que não era da área do trabalho não tinha muita sensibilidade, então essa discussão do trabalho não pago, ela era ainda muito embrionária no nosso meio, e a gente acabava sendo engolfada. Por exemplo, porque nesse momento explode a questão da violência e o racha dos grupos feministas em cima do SOS Corpo (...) Tinha havido crimes: é a época do seriado "Quem ama não mata", que é uma frase feminista. Foram as feministas de Belo Horizonte que inventaram "quem ama não mata", quando houve o assassinato da Eloísa Ballesteros. ${ }^{24}$

Ao contarmos essa história, de um feminismo mais hegemônico - e não nos enganemos pensando que, por ser mais hegemônico, os grupos tenham enfrentado poucas dificuldades para se estabelecer, ou as militantes, inclusive as acadêmicas, não tenham enfrentado profundos desafios em todas as esferas de suas vidas devido aos seus posicionamentos políticos como feministas ${ }^{25}$; contamos as histórias de mulheres intelectualizadas, em grande parte de camadas médias. Em esmagadora maioria heterossexuais, elas romperam barreiras ao ocupar espaços tradicionalmente masculinos na esfera pública enquanto eram, também, casadas ou divorciadas, mães de família desempenhando, se não todas, muitas das atividades que eram esperadas das mães de família de camadas médias daquela geração.

O que isso significava? Em larga medida, significava que não desempenhavam elas próprias grande parte do trabalho doméstico para suas famílias, como acontecia com a maioria das donas de casa $e$

\footnotetext{
${ }_{22}$ MELLO, Soraia Carolina de. Feminismos de segunda onda no Cone Sul problematizando o trabalho doméstico (1970 1989). Dissertação (Mestrado em História Cultural), Florianópolis/UFSC, 2010.

${ }^{23}$ MELLO, Soraia Carolina de. Discussões feministas na imprensa para mulheres: revista Claudia e o trabalho doméstico (1970-1989). Florianópolis. Tese (Doutorado em História) - UFSC, 2016.

${ }^{24}$ Entrevista com Hildete Pereira de Melo Hermes de Araujo, em Florianópolis, no dia 04/08/2017, realizada por Soraia Carolina de Mello, filmada por Elaine Schmitt e transcrita por Alina Nunes e Valéria Machado. Breve reportagem que aborda os feminicídios no estado de Minas Gerais e suas repercussões no começo dos anos 1980 pode ser acessada em GUIMARÃES, Katia. Mais de 40 anos após Ângela Diniz, Minas continua campeã em feminicídios. Socialista Morena. 12 de dezembro de 2017. Disponível em: http://www.socialistamorena.com.br/mais-de-40-anos-apos-morte-de-angela-diniz-minascontinua-campea-em-feminicidios/ Acesso em 14/04/2018.

${ }^{25}$ Hildete Pereira de Melo também aborda essa questão em sua entrevista, explicando que nem sua dissertação, nem sua tese, falavam de mulheres ou tinham temáticas feministas, devido à dificuldade em se debater essas questões nos departamentos de Economia no Brasil nas décadas de 1970 e 1980. Ela afirma que "não ousou" nesse sentido, apesar de ter nesse período já pronunciada militância feminista. Sua dissertação data de 1979 e sua tese de 1993.
} 
acontece ainda em nossos dias, mas que tinham responsabilidade sobre aquilo que, por estarem ocupadas com profissões, carreira e militância, não poderiam desempenhar. Então a elas cabia delegar a outras mulheres, de condição social mais precária que aquela delas próprias, essas tarefas. As empregadas domésticas, que desempenhavam também as funções de babás, governantas $e$ cozinheiras, trabalharam e ainda trabalham para as famílias de muitas feministas brasileiras. Apesar da responsabilidade por gerenciar esse trabalho, encontrar e contratar alguém, e mesmo executar essas funções na ausência da pessoa contratada, via de regra, recair sobre essas mães de família feministas, havia essa diferenciação entre quem de fato realizava o trabalho doméstico e as donas de casa que contavam com empregadas.

Existem inúmeros fatores a serem examinados nesse quesito: a dificuldade em levar o discurso do "pessoal é politico" para as relações familiares no que se tratava de divisão de tarefas e repartição do trabalho doméstico entre os membros da família; a profunda desiguldade de renda latino-americana que permitia e permite que mesmo famílias de camadas médias ou média-baixas possam contratar empregadas, nem que seja como diaristas; e um certo constrangimento das feministas de camadas médias dessa geração por entenderem que sua inserção na esfera pública só foi possível devido a essa profunda desigualdade e à exploração do trabalho de mulheres que viviam em situações mais vulneráveis que elas mesmas, como podemos observar no discurso de Hildete Pereira de Melo.

Agora, o emprego doméstico... esse... nós éramos beneficiadas dele. Todo mundo tinha empregada, quer dizer, podia tratar bem, pagar o justo, mas nós somos fruto dessa sociedade na qual para fazer política leva tempo, toma tempo sair de casa, então era o recuo que ficou. Eu fiz a história delas, do Rio, das associações, era a Nair Jane, que é um monumento de empregada doméstica, ainda está lutando até hoje, é a presidenta do Sindicato de Nova Iguaçu. E depois eu não fiz mais nada. Eu fui trabalhar novamente com empregada doméstica na década de 90 , quando eu comecei a trabalhar muito com o mercado de trabalho, numa pesquisa do IPEA [Instituto de Pesquisa Econômica Aplicada]. (...) Foi 96 isso, fui surpreendida com o sucesso. Esse artigo a Estudos Feministas publicou em 98, o artigo (...) já esmiuçando a PNAD [Pesquisa Nacional por Amostra de Domicílios] e tal. A partir daí ele entrou na agenda... eu diria que antes, tinha estudos, assim, mais pontuais, com olhar sociológico, mas não com número para mostrar que a ocupação das domésticas é a principal ocupação das mulheres brasileiras. ${ }^{26}$

A questão de raça e classe que perpassa o emprego doméstico no Brasil é histórica e persistente. Como apontado por bibliografia de referência, ${ }^{27}$ apenas em sociedades com profundas desigualdades sociais a larga presença do emprego doméstico pode ocorrer. Ou seja, é necessário que a renda média dos estratos médios seja tão mais alta que a renda média das classes trabalhadoras, a ponto de ser possível e razoável, para as famílias, contratar uma pessoa para trabalhar integralmente ou meio período como empregada doméstica. A maior parte das famílias que possuem empregadas domésticas não poderiam pagar qualquer outro tipo de trabalho nesses termos. Em sociedades com uma distribuição de renda mais equitativa o emprego doméstico contratado por camadas médias não existe. A diminuição percentual do emprego doméstico no Brasil observada até 2015 foi freada pela crise econômica, que fez essa ocupação crescer de novo. ${ }^{28}$

Cabe aqui um importante debate sobre interseccionalidades ${ }^{29}$, quando pensamos especificamente na ocupação da empregada doméstica. Uma ocupação estigmatizada, ${ }^{30}$ privada de direitos adquiridos

\footnotetext{
${ }^{26}$ Entrevista com Hildete Pereira de Melo Hermes de Araujo, em Florianópolis, no dia 04/08/2017, realizada por Soraia Carolina de Mello, filmada por Elaine Schmitt e transcrita por Alina Nunes e Valéria Machado.

${ }^{27}$ MILKMAN, Ruth; REESE, Ellen; ROTH, Benita. A macrossociologia do trabalho doméstico remunerado. Revista Latinoamericana de Estudios del Trabajo. Gênero, Tecnologia e Trabalho. São Paulo: Ano 4, n.7, 1998, Alast.

${ }^{28}$ VIECELI, Cristina Pereira; FURNO, Juliane da Costa; HORN, Carlos Henrique. Recessão econômica e emprego doméstico o Brasil. Gênero, Niterói, v.18, n.1, p. 26-55, 2017.

${ }^{29}$ Para esse debate indicamos ao menos CRENSHAW, Kimberlé. Documento para encontro de especialistas em aspectos da discriminação racial relativos ao gênero. Estudos Feministas, v. 10, p. 171-188, n.1/2002; DAVIS, Angela. Mulheres, raça e classe. São Paulo: Boitempo, 2016; e EVARISTO, Conceição. Insubmissas lágrimas de mulheres. Belo Horizonte: Nandyala, 2011.

30 Já na década de 1970 Heleieth Saffiotti comentava como muitas mulheres escolhiam ocupações pior remuneradas para fugir do estigma de serem empregadas domésticas. SAFFIOTI, Heleieth. Emprego doméstico e capitalismo. São Paulo: Vozes, 316 SÆCUlUM - ReVISTA DE HistóRIa [39]; João Pessoa, jul./dez. 2018.
} 
por outras categorias há décadas, que sempre ocupou principalmente mulheres negras e pardas, é representativa do racismo estrutural, da desigualdade de gênero e das complicadas relações intragênero brasileiras, no que se refere a empregadas e patroas. ${ }^{31}$ Respondendo, em 2017, a 14,6\% ${ }^{32}$ dos empregos formais das mulheres brasileiras, em 2015 pouco mais de $40 \%$ dessas trabalhadoras eram, segundo o IPEA ${ }^{33}$, brancas, marcando ainda sua maioria de pardas e negras. Levando em conta que o Brasil possui, segundo a OIT, uma das maiores, se não a maior população de empregadas domésticas do mundo, ${ }^{34}$ e que nas décadas de 1970 e 1980 essas desigualdades eram marcadamente mais profundas (apesar de não termos dados estatísticos daquelas décadas sobre as empregadas como temos hoje) e os direitos trabalhistas mais restritos ${ }^{35}$, podemos considerar o peso desse debate para os feminismos brasileiros, daquelas décadas e também de nossos dias.

Esses são fatores pouco discutidos pelas feministas do período ${ }^{36}$, que costumavam se enxergar em comparação com as mulheres das classes trabalhadoras, se entendendo como "menos oprimidas" 37 , posição que também precisa ser articulada com a força das teorias marxistas nos feminismos dessa geração no Brasil. Desse modo, não se aprofundaram muito os debates sobre a divisão de tarefas nos lares de camadas médias ${ }^{38}$ ou noções como a de "maternidade transferida", cunhada por uma das feministas dessa geração, Suely Gomes Costa, ${ }^{39}$ anos mais tarde. O que não quer dizer que a questão não tenha sido abordada.

Além de material encontrado nos três mais citados periódicos feministas brasileiros dos anos 1970 e 80 (Brasil Mulher - 1975-1980, Nós Mulheres - 1976-1978 e Mulherio - 1981-1988), assim como material bibliográfico ${ }^{40}$ que circulava pelo país, a temática trabalho tinha espaço cativo nesses feminismos tão atravessados pelo marxismo. E nesse espaço, era possível debater o trabalho não pago, mesmo que fosse muitas vezes visto como um "problema das outras" e não delas mesmas, das feministas com vida profissional e ampla atuação na esfera pública.

- Então essa questão não era uma questão trabalhada. (...) Antes do NEIM [Núcleo de Estudos Interdisciplinares sobre a Mulher] ser fundado em 1983 lá na Bahia, a Fanny Tabak, ela fez o Núcleo de Estudos da Mulher na PUC [Pontifícia Universidade Católica]. Tá? Que eu frequentei muito. A primeira vez que eu falei, não dar aula, que eu falei em público, foi numa conferência arrumada pelo núcleo da PUC, junto com o Departamento de Ciências Sociais da PUC, sobre mulher no mercado de trabalho. Não fui eu que fui convidada, foi a Branca [Moreira Alves], mas a Branca disse:

1978. Referência semelhante pode ser encontrada em ROSTAGNOL, Susana. Las trabajadoras en el servicio doméstico. Mujer y trabajo n 4. Montevideo: CIEDUR, 1988, p. 32, quando se diz que "Todas as empregadas domésticas entrevistadas querem que seus filhos estudem. No caso das filhas, querem que estudem para que não tenham que trabalhar como empregadas domésticas." Minha tradução.

${ }^{31}$ KOFES, Suely. Mulher, mulheres: identidade, diferença e desigualdade na relação entre patroas e empregadas domésticas. Campinas: Unicamp, 2001.

${ }^{32}$ WENTZEL, Marina. O que faz o Brasil ter a maior população de domésticas do mundo. BBC News Brasil. 26 de fevereiro de 2018. Disponível em https://www.bbc.com/portuguese/brasil-43120953. Acessado em 12/10/2018.

33 Dados disponíveis em http://www.ipea.gov.br/retrato/indicadores trabalho domestico remunerado.html Acessado em $12 / 10 / 2018$.

${ }^{34}$ Segundo dados de 2017, "o país emprega cerca de 7 milhões de pessoas no setor - o maior grupo no mundo. São três empregados para cada grupo de 100 habitantes - e a liderança brasileira nesse ranking só é contestada pela informalidade e falta de dados confiáveis de outros países." WENTZEL, Marina. O que faz o Brasil ter a maior população de domésticas do mundo...

${ }^{35}$ Sobre essa questão, Cf. Capítulo 2 em MELLO, Soraia Carolina de. Feminismos de segunda onda no Cone Sul problematizando o trabalho doméstico (1970 - 1989). Dissertação (Mestrado em História Cultural), Florianópolis/UFSC, 2010.

${ }^{36}$ É possível acessar tal debate em AZEREDO, Sandra Maria da Mata. Relações entre empregadas e patroas: reflexões sobre o feminismo em países multi-raciais. In: COSTA, Albertina de Oliveira; BRUSCHINI, Cristina (org.). Rebeldia e submissão. Estudos sobre condição feminina. São Paulo: Vértice/Revista dos Tribunais/Fundação Carlos Chagas, 1989.

${ }^{37}$ Cf. editorial Nós Mulheres, São Paulo, n.1, junho de 1976.

${ }^{38}$ Temos a exceção de Carmen da Silva, que discutiu essa questão na grande imprensa comercial. Exemplo em SILVA, Carmen da. Na luta para se afirmar a mulher tem que ser... Super mulher! Claudia. São Paulo, n.210, Ano XVIII, março de 1979, p. 168-169.

${ }^{39}$ COSTA, Suely Gomes. Proteção social, maternidade transferida e lutas pela saúde reprodutiva. Estudos Feministas, Florianópolis, v.10, n.2, p. 301-323, jul. 2002.

${ }^{40}$ Exemplo em PRADO, Danda. Ser esposa - a mais antiga profissão. São Paulo: Brasiliense, 1979, mas também nos clássicos internacionais BEAUVOIR, Simone de. O Segundo Sexo: Fatos e Mitos. V.1. Rio de Janeiro: Nova Fronteira, 1970 e FRIEDAN, Betty. Mística Feminina. Petrópolis: Vozes, 1971. 
Hildete, pra falar de trabalho é você, não sou eu. Vai lá! E eu falei: ai meu Deus, como é que eu vou falar? Nunca falei em público! Uma plateia de 150 pessoas que não eram os alunos de economia, com quem eu estava acostumada a falar, e aí eu falei sobre invisibilidade do trabalho da mulher! Eu me lembro até hoje. Depois eu escrevi um artigo para o Jornal dos Economistas sobre a invisibilidade do trabalho feminino. Do trabalho não pago! (risos). A gente já estava abrindo essa discussão, porque essa é uma discussão que aparecia quando você trabalhava salário igual, ou tem o problema da desigualdade do salário, mas também quando tem a sobrecarga do outro trabalho. Então foi primeira vez, porque em economia...

- Em que ano que foi esse artigo?

- 78. $(\ldots)^{41}$

Nesse sentido, a entrevista concedida por Luci Choinacki nos traz um contraponto muito importante. Apesar de ter ocupado cargos políticos de destaque, como deputada estadual e federal, Luci Choinacki tem uma história de vida muito diferente daquela da maior parte das brasileiras que encabeçaram os mais conhecidos grupos feministas na década de 1970. Inclusive porque sua militância data da década de 1980. Agricultora, tinha o desejo de ser professora, mas não pôde continuar os estudos, em função de ser filha primogênita de sete irmãos, os quais precisou ajudar a criar. É mãe de quatro filhos, um deles deficiente, com necessidade de cuidados específicos. Ingressa na vida política através dos movimentos sociais ligados à Teologia da Libertação, à Pastoral da Terra, através da qual se envolve no Movimento de Trabalhadores Sem Terra (MST) e no Movimento de Mulheres Camponesas (MMC) de Santa Catarina.

Essas questões se refletem em sua atuação política. Luci Choinacki obteve importantes resultados da militância dentro de seus mandatos, no que se refere a: direitos trabalhistas antes negados às trabalhadoras rurais (como a licença-maternidade ou aposentadoria); aposentadoria para donas de casa de baixa renda (uma população que antes dessa conquista ficava sem previdência social, totalmente dependente de familiares); debates sobre feminização da pobreza; e também no que hoje chamaríamos de políticas do cuidado. Essas características são ainda ressaltadas em sua vida na atualidade, quando a indagamos sobre esse período.

Olha, de início, assim, os grupos feministas (...) tinham um pouco de dificuldade. Depois foi se abrindo o processo, para as agricultoras principalmente, com a questão do trabalho doméstico. O trabalho doméstico foi uma coisa muito, muito dura pra ser debatida. Nós criamos uma forma de as mulheres donas de casa se aposentarem, aí criou uma crise de concepções, mas não era: a mulher tem que ficar em casa! Mas reconhecer que existia um público, isolado de todo o processo e que precisava de um tratamento diferenciado. É como uma transição, então a gente teve problemas de início, depois a gente fez muito debate em todo o Brasil, nós fizemos seminários, plenárias, aí um grande grupo de feministas assumiu a bandeira e foi junto fazer conferência e discussão: Hildete Pereira, não sei se alguém conhece, a Doutora Salete, que era uma de juíza lá do Rio de Janeiro, aqui do estado [Santa Catarina] Joana Pedro, e assim vai indo. Mas assim todo o Brasil, a gente reuniu muitas mulheres depois, que assumiram a causa. Inclusive eu fiz uma comissão parlamentar, para fazer um trabalho: a pobreza tem rosto, que é o rosto das mulheres. Porque em qualquer crise, qualquer golpe que dá, primeiro quem sofre a demissão, a punição são as mulheres, porque sentem o custo da alimentação, o cuidado dos filhos, a doença em casa, as pessoas especiais para cuidar, sobra para elas, e eu falo isso com conhecimento de causa, não é? Então a gente foi fazendo essa discussão e ela pegou uma dimensão muito grande. Inclusive teve pesquisas: "quanto que seria se tivesse que pagar o trabalho doméstico que as mulheres fazem?" (...) O trabalho gratuito que as mulheres estão prestando para a sociedade, que não é reconhecido de nenhuma forma. ${ }^{42}$

\footnotetext{
${ }^{41}$ Entrevista com Hildete Pereira de Melo Hermes de Araujo, em Florianópolis, no dia 04/08/2017, realizada por Soraia Carolina de Mello, filmada por Elaine Schmitt e transcrita por Alina Nunes e Valéria Machado.

${ }^{42}$ Entrevista com Luci Teresinha Choinacki, em Florianópolis, no dia 25/09/2017, realizada por Soraia Carolina de Mello, filmada por Elaine Schmitt e transcrita por Jeferson Ramos. 
Luci continua a entrevista comentando a necessidade de aparelhos do Estado voltados à distribuição de renda e socialização do trabalho de cuidado, entendendo que esse trabalho recai sobretudo sobre as mulheres. Ela traz demandas feministas, mas sua formação política está muito mais ligada aos movimentos de mulheres. Ruth Cardoso ${ }^{43}$, em texto publicado em 1987, durante o período dos debates sobre a elaboração da atual Carta Constitucional brasileira, diferencia essas vertentes como movimentos populares e movimentos libertários. Os feminismos, não tão diretamente ligados a questõs de ordem geral, como creches ou custo de vida, quanto os movimentos de base, estariam entre os movimentos libertários. Contudo, tanto nesse trabalho teórico de Ruth Cardoso quanto na memória de Luci Choinacki sobre essas pautas, podemos perceber a articulação entre os movimentos de mulheres e os feministas.

Outra articulação importante no discurso de Luci Choinacki se refere à dicotomia urbano/rural, a qual ela não parece querer aprofundar ao memorar as pautas sobre trabalho doméstico não pago. Em seu discurso, o debate da divisão das tarefas no lar parece ser uma pauta comum a essas esferas.

- É totalmente diferente, mas nos dois setores de mulheres, tanto urbano quanto rural, pesa para as mulheres, ainda infelizmente. $\mathrm{O}$ trabalho mais cansativo, diário, de não ter a contribuição da família participar, dos filhos, do marido, do seu companheiro, seja o que for, participar do trabalho. Eu vou dizer, quando tem participação, as coisas fluem diferente, a gente se sente melhor, até porque se um cozinha e o outro lava, é diferente... E também para precisar pedir é chato, pede uma vez, duas, depois tu se enche de estar pedindo, então as pessoas têm que pegar como uma concepção de vida, de valores.

- Seu próprio sustento, de todo mundo...

- É, exatamente, de participar, porque se uma pessoa só faz, a gente se cansa, enjoa de fazer. Mas se quem está junto participa, muda, a vida fica diferente. Se tem que fazer sozinha, tu vai olhando para a outra pessoa lá sentada, acomodada, daqui a pouco tu tem vontade de virar a cadeira pra ver se ela descola de lá! (risos) ${ }^{44}$

Essa questão acerca da família nos leva a outra questão familiar envolvendo os feminismos, que remete à maternidade e também à vida doméstica. Apesar de Fani Miranda Tabak, neta de um dos mais destacados nomes do feminismo brasileiro do período (Fanny Tabak, citada anteriormente, fundadora do primeiro Núcleo de Estudos Sobre a Mulher na PUC-Rio), não ter abordado muito o trabalho doméstico em sua entrevista, nos chama a atenção nesse contexto, ao refletir sobre feminismo intergeracional, como ela observa que a posição de feminista é reconhecida e admirada por muitas pessoas, mas nem sempre bem quista na família. Ela nos falou das memórias sobre sua avó, mas também sobre si própria, como acadêmica. Uma mãe (ou avó) com posição social destacada geralmente não pode desempenhar o que tradicionalmente se espera de uma mãe que, conforme já comentava Danda Prado na década de $1970^{45}$, é basicamente servir à família incondicionalmente, com muito amor.

Acho que o impacto do feminismo sobre a família é muito diferente do que sobre as pessoas que se inspiram em você. Sobre a família é uma coisa mais complicada, mais delicada, acho que eu vivo um pouco isso hoje na prática com as minhas filhas. Então, às vezes não é fácil para a família perceber aquilo que os outros percebem, que é importante em você, ou que torna você uma pessoa inspiradora. Às vezes isso para a família pode ser ao contrário. (...) Acho que é difícil sobretudo para mulher, existe uma série de opiniões sobre a mulher, ninguém nunca perguntou o que ela pensa de fato. Acho que o dia em que falar todo mundo sai correndo, mas por sorte os filhos não perguntam para gente: mãe o que você pensa de fato de ser mãe? Então a gente fica só nas entrelinhas das coisas, porque é uma representação muito difícil. ${ }^{46}$

\footnotetext{
${ }^{43}$ CARDOSO, Ruth Correa Leite. As mulheres e a democracia. Revista de Ciências Sociais, Porto Alegre, vol.1, n. 2, p. 139304, 1987.

${ }^{44}$ Entrevista com Luci Teresinha Choinacki, em Florianópolis, no dia 25/09/2017, realizada por Soraia Carolina de Mello, filmada por Elaine Schmitt e transcrita por Jeferson Ramos.

${ }^{45}$ PRADO, Danda. Ser esposa: a mais antiga profissão. São Paulo: Brasiliense, 1979.

${ }^{46}$ Entrevista com Fani Miranda Tabak, em Florianópolis, no dia 01/08/2017, realizada por Soraia Carolina de Mello, filmada por Elaine Schmitt e transcrita por Luana Balieiro Cosme. 
Essas diferenças de percepções sobre o trabalho doméstico e as resultantes expectativas depositadas sobre as mulheres, principalmente as que são mães, se dão de formas muito variadas desde os anos 1960 e 1970 até nossos dias. Contudo, continuidades podem ser observadas, e análises recentes sobre trabalho doméstico e o trabalho reprodutivo realizado pelas mulheres apontam esse trabalho como obstáculo ao acesso pleno à cidadania. Sem questionar a importância do trabalho reprodutivo - muito pelo contrário -, há disponível ampla bibliografia, tributária dos estudos feministas e de gênero, que percebe um "uso presumido" que o Estado e a sociedade faz do trabalho considerado feminino, uso esse que interfere diretamente no acesso das mulheres a direitos fundamentais ${ }^{47}$, quando parcela considerável do tempo e da energia delas é dispensada em tarefas de manutenção da coletividade. ${ }^{48}$

\section{A intrincada relação do trabalho doméstico como pauta feminista no contexto de fragilidade da democracia brasileira}

O trabalho doméstico, remunerado e não remunerado, certamente é uma dentre as diversas pautas históricas de reivindicação feminista não resolvidas, ou com avanços muito tímidos no decorrer das décadas. Temáticas que hoje estão no foco da pauta feminista brasileira, e que são centrais para entendermos o Brasil, como as interseccionalidades, em especial levando em conta os debates raciais, não surgem com força no recorte das entrevistas aqui apresentadas, apesar de aparecerem nas entrelinhas do debate. Isso pode ter muita relação com as perguntas que fizemos nas entrevistas, disponíveis ao final do artigo, que foram muito focadas nos feminismos, nas esquerdas e na democracia de forma generalizada. As mulheres ligadas aos movimentos negros que entrevistamos para o projeto, ${ }^{49}$ contudo, não desarticulam o debate democrático do combate ao racismo. Mas estas entrevistas não aprofundaram o debate sobre trabalho doméstico, recorte estabelecido para o texto aqui apresentado e, por isso, não foram utilizadas nesta análise.

Apesar do debate interseccional não ser profundamente explorado nos trechos de entrevistas aqui selecionados, alguns dos fatores levantados nessas memórias são de uma atualidade assombrosa. Hildete Pereira de Melo nos lembra da permanência, devidamente repaginada, não uma permanência anacrônica mas ainda uma permanência, de práticas, debates, pautas e da própria agenda feminista.

As discussões, hoje quando eu vejo o movimento feminista falando, eu falo: ai, voltou tudo! A pauta não muda! (risos). É interessante observar, porque a meninada de hoje acha que está fazendo uma grande novidade. Elas trocaram um pouco os adjetivos $e$ os conceitos, mas no fundo é a mesma questão. Por exemplo, eu estou na PartidA, com a turma lá no Rio, e a discussão, eu fico olhando e é ótimo, porque parece que eu estou vivendo 78, 77, no Centro da Mulher Brasileira. E não tem coordenação, $e$ tem coordenação, quem manda, quem não manda, qual é a voz? Olha, é parecido. Claro que não é a mesma coisa, porque quem viveu essa época não são vocês que vivem a atualidade, mas essa é a trajetória. ${ }^{50}$

A partir dessa observação, podemos nos colocar algumas questões. $\mathrm{O}$ quanto os discursos e as memórias dessas mulheres nos ajudam a pensar a história dos debates acerca do trabalho doméstico $e$ dos feminismos como foco de conflito social no Brasil partindo da ditadura militar, mas também em nossos dias? Quantos dos problemas apontados por elas nos depoimentos apresentados, e outros também encontrados nas produções feministas do passado, em panfletos, periódicos, grupos de reflexão e palavras de ordem nas ruas ecoam com profundo significado para as mulheres brasileiras ainda na atualidade? O quanto a questão do trabalho não pago que as mulheres prestam para suas famílias e para a sociedade, do qual nosso Estado é absolutamente dependente, pesa quantitativa $e$

\footnotetext{
${ }^{47}$ MARIANO, Silvana A.; SOUZA, Márcio F. de. Conciliação e tensões entre trabalho e família para mulheres titulares do Programa Bolsa Família. Revista Brasileira de Ciência Política, Brasília, n.18, p. 147-177, dez. 2015.

${ }^{48}$ ABREU, Alice Rangel Paiva [et al.] (org.). Gênero e trabalho no Brasil e na França: perspectivas interseccionais. São Paulo: Boitempo, 2016.

${ }^{49}$ Podemos citar as entrevistas de Analba Brazão Teixeira e Nilma Lino Gomes, ambas de 2017 (referência completa suprimida para evitar identificação de autoria).

${ }^{50}$ Entrevista com Hildete Pereira de Melo...
} 
qualitativamente, de diferentes formas, nas escolhas e opções de vida das mulheres brasileiras?

Dentro da perspectiva do golpe de estado em 1964 e do regime de exceção nos que o seguem, esses debates ganham destaque. Podemos observar nesse sentido, por exemplo, os esforços do governo militar em exaltar a importância da família tradicional para a saúde física e mental da juventude, frisando a imprescindível figura materna no $\operatorname{lar}^{51}$, o que destaca o caráter conservador do regime e sua preocupação com as mudanças que vinham ocorrendo no modelo tradicional de família. ${ }^{52}$ Essas são questões que nos ajudam a pensar os avanços conservadores na contemporaneidade, construir paralelos e reconhecer o valor de debates clássicos a respeito ainda para nossa geração.

Quantos paralelos podemos construir entre a ditadura e o momento político em que estamos vivendo em que, conforme comentado no "Ciclo de Debates: Golpe de 2016 e Futuro da Democracia no Brasil" 53 , direitos básicos são ceifados em nome do avanço de interesses do capital local $e$ internacional, e vivemos uma situação política que não é ditadura mas também não é democracia? Essas são questões centrais no cenário político brasileiro contemporâneo e também na produção feminista, historiográfica e interdisciplinar, e para as quais não existe uma resposta simples. $\mathrm{O}$ que não nos impedirá de continuar analisando, observando e construindo relações na busca por respostas ou elucidações, em um esforço coletivo essencial e urgente para trilhar novos caminhos democráticos.

\section{Roteiro das entrevistas ${ }^{54}$}

1) No período de 1964 a 1985 identificou-se com o feminismo? E depois de 85?

2) Em quais circunstâncias?

3) Como viveu o período da ditadura (o que fazia, e onde)? E a abertura política?

4) Como você via a relação entre feminismo e esquerdas durante a ditadura?

5) Quais leituras feministas e/ou pessoas que a/o influenciaram?

6) Participou de grupos de reflexão? Qual a influência destes grupos em sua identificação com o feminismo?

8) Quais os temas discutidos?

9) Divulgou estas ideias?

10) Por quais meios?

11) Participou de eventos, associações, organizações feministas?

12) Circulavam informações sobre as perseguições políticas e sobre as ditaduras nos outros países?

13) Você associaria o feminismo com a noção de conflito social naquele período? E hoje?

14) Considera-se feminista hoje?

15) Onde e como atua no campo feminista? Tem articulação com as esquerdas?

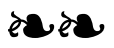

\footnotetext{
${ }^{51}$ DUARTE, Ana Rita Fonteles; LUCAS, Meize Regina de Lucena (Orgs.). As mobilizações do gênero pela ditadura militar brasileira - 1964 -1985. Fortaleza: Expressão Gráfica e Editora, 2014.

${ }^{52}$ COLLING, Ana Maria. 50 anos da ditadura no Brasil: questões feministas e de gênero. OPSIS, [S.1.], v. 15, n. 2, p. 370383, dez. 2015.

${ }^{53}$ O "Ciclo de Debates: Golpe de 2016 e Futuro da Democracia no Brasil" estava ocorrendo no Centro de Filosofia e Ciências Humanas (CFH) da Universidade Federal de Santa Catarina (UFSC) enquanto este texto foi pensado. O Ciclo realizado na UFSC, como tantos outros no Brasil, foi uma resposta da comunidade acadêmica do CFH às recentes ameaças aos princípios da liberdade de pensamento, à autonomia das Universidades e à soberania da cátedra. A atividade somou-se às iniciativas de diversas Universidades brasileiras em apoio ao Professor Luis Felipe Miguel, da Universidade de Brasília, que recentemente foi alvo de ameaças e de censura em razão da oferta de uma disciplina cujo título também se toma de empréstimo para nomear o evento no CFH. A programação pode ser acessada em http://noticias.ufsc.br/2018/03/ciclo-de-debates-o-golpe-de2016-e-o-futuro-da-democracia-no-brasil-comeca-nesta-quinta-no-cfh/ Fotos, vídeos e mais informações em $<$ https://www.facebook.com/events/175993446361225/. Acesso em 14/04/2018.

${ }^{54}$ Este questionário de base foi construído coletivamente por diversas componentes do Laboratório de Estudos de Gênero e História (LEGH) da Universidade Federal de Santa Catarina (UFSC) em pesquisas realizadas sobre a história dos feminismos brasileiros e do Cone Sul, desde o começo dos anos 2000. Foi um questionário utilizado por diversas pesquisas oriundas desse núcleo, e sofreu leves adaptações para o projeto "Mulheres de luta".
} 


\section{RESUMO}

Este artigo utiliza como fonte memórias de mulheres que foram militantes feministas durante a ditadura militar no Brasil e que também participaram da abertura política no país a partir de meados dos anos 1980. Nessas memórias investiga-se, do ponto de vista dessas mulheres, engajadas politicamente nos feminismos e muitas vezes nas esquerdas, as interlocuções entre as problematizações feministas acerca do trabalho doméstico e a perspectiva de sociedade democrática que se abre no período. Sob o slogan "feminismo no país e em casa", os debates feministas articularam público $e$ privado ao denunciar a carga de trabalho doméstico que era executada quase que exclusivamente pelas mulheres e suas consequências para o pleno acesso dessas à cidadania. Trabalha-se sob a perspectiva da história das mulheres e das relações de gênero, assim como dos debates historiográficos sobre memória e história oral, cruzando ampla bibliografia de referência sobre os feminismos de período, a ditadura e a abertura democrática. Desse modo, se pretende pensar a história do debate acerca do trabalho doméstico encabeçado por feministas dessa geração como um ponto fulcral para as mulheres nas novas perspectivas democráticas que se construíram no âmbito político brasileiro na segunda metade dos anos 1980 .

Palavras-chave: Trabalho doméstico; História dos feminismos; Ditadura e democracia brasileira.

\section{ABSTRACT}

This article utilizes as sources memoirs of women who were feminist militants during the military dictatorship in Brazil and who also participated in the political opening in the country from the mid1980s. In these memoirs are investigated, from the point of view of these women, who were politically engaged in feminisms and often in the left, the interlocutions between the feminist problematizations about domestic work and the perspectives of a democratic society that begins to be unveiled in the period. Under the slogan "feminism in country and at home", feminist debates articulated public and private by denouncing the domestic workload that was carried out almost exclusively by women and its consequences for full access to citizenship. The article is based on the perspective of women's history and gender relations, as well as the historiographic debates on memory and oral history, crossing a wide bibliography of reference on the feminisms of the period, dictatorship and democratic opening. In this way, the intention is to think the history of the debate about domestic work headed by feminists of this generation as a focal point for women in the new democratic perspectives that were built in the Brazilian political sphere in the second half of the 1980s.

Keywords: Domestic work, History of feminisms; Dictatorship and Brazilian democracy.

Artigo recebido em 31 jul. 2018.

Aprovado em 11 out. 2018 